\title{
Technology, Engineering, and Design Educator Professional Development Sys- tem Implementation: Initial Pilot Results
}

\section{Dr. Jeremy V Ernst, Virginia Tech}

Jeremy V. Ernst is an Assistant Professor in the Department of Teaching and Learning at Virginia Tech. He currently teaches graduate courses in STEM education foundations and contemporary issues in Integrative STEM Education. Jeremy specializes in research focused on dynamic intervention means for STEM education students categorized as at-risk of dropping out of school. He also has curriculum research and development experiences in technology, engineering, and design education.

\section{Miss Laura J. Segedin, Virginia Tech}

Laura J. Segedin is a Graduate Research Assistant for the Transforming Teaching through Implementing Inquiry project. She earned a Masters degree in Curriculum and Instruction with a specialization in Integrative STEM Education at Virginia Tech in the Spring of 2013. Laura has 12 years of teaching experience at the middle school level in Technology Education.

\section{Dr. Aaron C. Clark, North Carolina State University}

Aaron C. Clark is a Professor of Technology, Design, and Engineering Education within the College of Education and is the Director of Graduate Programs and Associate Department Head for the Department of Science, Technology, Engineering and Mathematics Education. He has worked in both industry and education. Dr. Clark's teaching specialties are in visual theory, 3-D modeling, technical animation, and STEM-based pedagogy. Research areas include graphics education, game art and design, scientific/technical visualization and professional development for technology and engineering education. $\mathrm{He}$ presents and publishes in both technical/technology education and engineering. He has been and continues to be a Principle Investigator on a variety of grants related to visualization and education and has focused his research in areas related to STEM curricula integration. Dr. Clark has been a member of the Engineering Design Graphics Division of the American Society for Engineering Education (ASEE) since 1995; and has served in leadership roles and on committees for the Division since that time, as well as for the K-12 Outreach Division. He has also served in various leadership roles in disciplines related to Career and Technical Education. Dr. Clark is recognized as a Distinguished Technology Educator by the International Technology Engineering Education Association. He currently consults to a variety of businesses, educational agencies and organizations.

\section{Dr. Vincent William DeLuca, North Carolina State University}

V. William DeLuca, Ed.D. Dr. DeLuca taught middle school, high school, undergraduate and graduate level technology education in his 30 year career as a teacher and researcher. He has extensive research and curriculum development experience in STEM disciplines. His research includes the study of thinking processes, teaching methods, and activities that improve technological problem-solving performance and creativity. He has expertise in developing technology and engineering education curriculum that integrates science, technology, engineering and mathematics (STEM) concepts. Dr. Deluca is Co-PI on NSF project Transforming Teaching through Implementing Inquiry (DRL 1118942). This project focuses on developing research-proven professional development resources that integrate teacher learning with assessment practice. The end product will constitute a professional development and research-proven cyber infrastructure for technology, engineering and design educators. 


\title{
Technology, Engineering, and Design Educator Professional Development System Implementation: Initial Pilot Results
}

\begin{abstract}
The Transforming Teaching through Implementing Inquiry $\left(\mathrm{T}^{2} \mathrm{I}^{2}\right)$ project is a four-year research and development effort, funded by the National Science Foundation, to create and research an online professional development system for grades 6-12 technology, engineering, and design educators. The system content targets implementation and instructional practice, as defined by National Board for Professional Teaching Standards (NBPTS), in support of quality classroom indicators for the promotion of student learning. Randomly selected middle school and high school technology, engineering, and design educators in five states (IL, KY, OH, NC, and VA) served as participants by: 1) completing the $\mathrm{T}^{2} \mathrm{I}^{2}$ online professional development materials, 2) submitting artifacts/evidences of practice, 3) administering a student STEM pre-assessment, 4) implementing a single consistent unit of instruction, 5) administering a student STEM postassessment. Pilot Year 1 (2012-2013 academic year) teacher outcome data, as measured by NBPTS criterion referenced metrics, is analyzed and reported in terms of ability to manage a learning environment, monitor a learning environment, adjust a learning environment to improve instruction, conduct self-assessment, and contribute to a learning community. This project is set to be an ongoing effort with the overall goal to improve instructional practices for K-12 engineering education.
\end{abstract}

\section{Introduction}

The numerous initiatives in STEM (Science, Technology, Engineering, and Mathematics) Education in the United States call for high quality professional development for STEM educators. ${ }^{1}$ Since professional development structures are varied, as are school districts, there is no one model that is proven to work for every teacher or school. ${ }^{2}$ Despite this fact, much can be learned from the organization that assesses teaching quality and awards educators with National Board Certification - the National Board for Professional Teaching Standards (NBPTS). The Transforming Teaching through Implementing Inquiry $\left(\mathrm{T}^{2} \mathrm{I}^{2}\right)$ project is a web-based professional development curriculum created specifically for technology, engineering and design educators to meet this need. Funded by the National Science Foundation, $\mathrm{T}^{2} \mathrm{I}^{2}$ is a four-year research and development effort out of Virginia Tech and North Carolina State University in collaboration with National Board Professional Teaching Standards.

Based on the assertion that there is no greater measure of excellence in teaching than National Board Certification, the $\mathrm{T}^{2} \mathrm{I}^{2}$ project parallels the goals of NBPTS. The $\mathrm{T}^{2} \mathrm{I}^{2}$ curriculum encourages teachers to improve their classroom practices, participate in professional activities, and increase student learning in STEM while practicing self-reflection. As educators engage in reflection about teaching and learning, they tend to improve their practice and increase student performance. ${ }^{3,4}$ These improvements are significant when educators pursue high quality professional development such as National Board Certification, even if they do not ultimately achieve certification. ${ }^{5} \mathrm{~T}^{2} \mathrm{I}^{2}$ capitalizes on this finding by creating a program that challenges 
teachers to reflect on and improve instruction without the cost or arduous journey toward certification.

$\mathrm{T}^{2} \mathrm{I}^{2}$ was designed to be a high quality yet flexible professional development program based on a number of research findings. At a time when conversations about educational reform are prevalent, educators need learning experiences that foster demonstrable and sustained growth. Practices such as critical reflection and experimentation allow teachers to become learners, applying new ideas and skills in their own contexts. ${ }^{4}$ Successful professional development focused on improving student performance demands a deliberate structure within a wellorganized and sufficient time frame. ${ }^{6}$ In addition, flexible, rigorous and ongoing professional development is recommended for creating positive changes in schools. ${ }^{7}$

This report will outline the research conducted during the Year 1 pilot year of the $\mathrm{T}^{2} \mathrm{I}^{2}$ program. Details of the curricular material will be highlighted as well as methodologies, results, and analyses of the data.

\section{Participants}

Participants were solicited via statewide listservs in technology education from five project states- Illinois, Kentucky, Ohio, North Carolina, and Virginia. A total of 190 people applied to take part in the $\mathrm{T}^{2} \mathrm{I}^{2}$ project, and they were stratified into two groups: middle school and high school teachers. Sixteen pilot teachers were randomly selected for the 2012-2013 Year 1 pilot, eight from each group. Each teacher received a personalized letter inviting individual participation, an outline of pilot responsibilities, a letter of commitment to sign and return, and a listing of the $\mathrm{T}^{2} \mathrm{I}^{2}$ Learning Objects. $\mathrm{T}^{2} \mathrm{I}^{2}$ Project Learning Objects are granular, scalable, and adaptable professional development learning modules that teachers interface with and implement in their existing learning environments. The Year 1 pilot began in September of 2012 and concluded in May of 2013. Throughout the pilot year, a number of teachers were not able to participate in the project. As a result, only six teachers submitted data.

\section{$T^{2} I^{2}$ online professional development materials}

The $\mathrm{T}^{2} \mathrm{I}^{2}$ materials were created to meet the need for high quality professional development for technology, engineering, and design educators. During a one-week writing workshop, a 20member writing team of NBPTS certified teachers, in-service technology, engineering and design educators, and teacher education university faculty wrote the content for $\mathrm{T}^{2} \mathrm{I}^{2}$. Paralleling many of the themes and requirements of National Board Certification in Career and Technical Education, the $\mathrm{T}^{2} \mathrm{I}^{2}$ content uniquely addresses best practices in teaching within a technology and engineering context.

The content is divided into 17 Learning Objects, which are research-based guides for readers to learn about specific topics in teaching and their classroom applications. The Learning Objects are situated within the context of learning through inquiry, centered on engineering design-based problem solving strategies, while maintaining alignment with the NBPTS. The Learning Objects fall under one of four Units, whose titles directly align with the four National Board portfolio 
entries. (Please refer to Table 1 for Unit titles, Learning Object names, and brief descriptions of the Learning Objects.)

Table 1: The $\mathrm{T}^{2} \mathrm{I}^{2}$ units and learning objects as on project website ${ }^{9}$

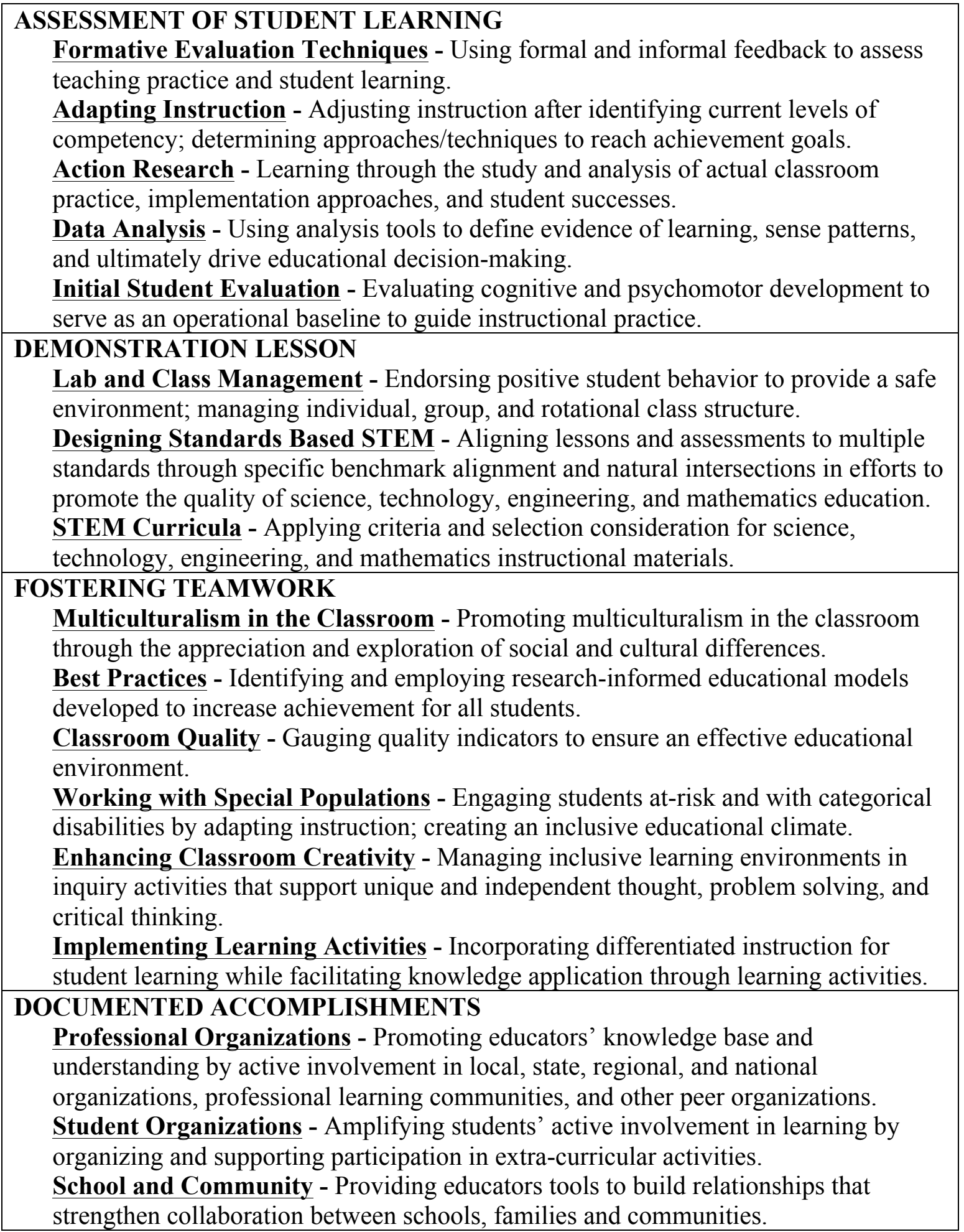


When participants read the content in a Learning Object and interact with any relevant media, they will be prompted to take a five-item quiz to check their understanding. These quizzes are merely for self-assessment and can be retaken as many times as needed. Although the most recent quiz score is recorded in the system, the $\mathrm{T}^{2} \mathrm{I}^{2}$ research team does not use the quiz data to assess teacher performance. After all of the Learning Objects in one Unit are completed, participants can then complete a two-page written commentary about their teaching practices and a five-minute video commentary of their classroom implementation of the topics (if applicable) according to the National Board aligned prompt(s) in each unit (see Appendix A for an example requirement and prompt). For more information on the $\mathrm{T}^{2} \mathrm{I}^{2}$ professional development materials, please refer to Ernst, Clark, DeLuca, \& Bottomley, $2013^{8}$.

Pilot teachers may exercise a great deal of freedom when using the $\mathrm{T}^{2} \mathrm{I}^{2}$ system. First, there is no set order for how teachers go through the content. Even though Learning Objects are grouped by Unit, they do not have to be read in any particular arrangement. This allows teachers to choose areas that interest them the most to read first. Second, although teachers must submit all of their Unit entries by a certain due date, they may start and finish the $\mathrm{T}^{2} \mathrm{I}^{2}$ program at any time. Third, the online system enables teachers to participate at their leisure without having to be in a certain location at a certain time. All of these conveniences are generally not available when participating in professional development such as a conference, workshop, or graduate course.

One of the guiding principles of the $\mathrm{T}^{2} \mathrm{I}^{2}$ system materials is flexibility. As such, the entire content of the $\mathrm{T}^{2} \mathrm{I}^{2}$ professional development material is housed online (http://t2i2.ncsu.edu/) and can be accessed by pilot teachers at any time in the year from any internet-accessible device. The system was developed from scratch with unique capabilities for administrators and users alike. User data such as most recent login timestamps, number of quiz attempts, and Unit submissions were viewed by administrators and used to monitor teachers' progress and make system adjustments when necessary. Tracking information such as how much time teachers spend reading the content of a Learning Object alerted administrators in Year 1 that the content of a particular Learning Object needed to be condensed, and this need was addressed in the Year 2 writing workshop. Based on input received throughout the year, a feedback system was included mid-year to give teachers the capability to send comments about each Learning Object to administrators so that changes could be implemented immediately and so that feedback could be forwarded to the writers for more intricate changes during the summer writing workshop. User data in the Year 1 pilot were extremely important for improving the quality of the material for the Year 2 pilot.

\section{Data Collection and Analysis}

As teachers progressed through the $\mathrm{T}^{2} \mathrm{I}^{2}$ curriculum at their own pace throughout the year, a variety of data were gathered. Time-on-task and a score for the five-item quiz were documented for each Learning Object. Teachers' required written commentaries (total of four) and video commentaries (total of two) were scored by a National Board Certified teacher using an adapted rubric and four-point scoring system. In addition, student scores on a 30-item STEM-based pretest and post-test were calculated and analyzed to determine competency gains/losses in science, mathematics, and/or technology education. 
Quantitative research methods were employed to form the basis of this research project. Researchers used non-parametric statistical analysis to determine each teacher's ability to manage, monitor, and adjust the learning environment in his/her classroom, as well as student gains in science, mathematics, and technology education. A one-group pretest/posttest design was utilized for student gains/losses in science, mathematics, and/or technology education.

Although the content of each Learning Object differs, the format for all is consistent: NBPTS alignment, a brief description of the content, learning objectives, impact on learning (comprises the main body of content), step-by-step procedures in the classroom for implementation, a selfcheck list, an appendix with useful links and citations, and a five-question assessment quiz. Teachers read through the research-based Learning Object and take an assessment to check their understanding of the content. Data was collected for time on task (see Table 2, also seen in ${ }^{8}$ ), as well as average number of quiz attempts and average quiz scores for Year 1 pilot teachers (Table $3)$.

Table 2: Time on task for Year 1 pilot teachers, ( $n$ ranges from 7-11 pilot teachers).

\begin{tabular}{llll}
\hline & Total Unit & $\begin{array}{l}\text { Average } \\
\text { Unique Unit } \\
\text { Views/Day }\end{array}$ & $\begin{array}{l}\text { Average Time } \\
\text { Spent on Unit } \\
\text { (in minutes) }\end{array}$ \\
\hline Assessment of Student Learning & 1001 & 3.65 & 203.4 \\
Demonstration Lesson & 395 & 1.59 & 170.2 \\
Fostering Teamwork & 376 & 2.00 & 359.4 \\
Documented Accomplishments & 205 & 0.95 & 176.2 \\
\hline
\end{tabular}

Collecting data for time on task helped the $\mathrm{T}^{2} \mathrm{I}^{2}$ research team identify units or Learning Objects that were taking pilot teachers a large amount of time to complete, and this information was used to make modifications for Year 2. For example, the data in Table 2 indicates that the Fostering Teamwork unit took the longest to complete, with an average of one hour per Learning Object (359.4 minutes divided among six Learning Objects in the unit). Both Demonstration Lesson and Documented Accomplishments also averaged around one hour per Learning Object, as both units contained only three Learning Objects. Assessment of Student Learning, on the other hand, averaged 40 minutes per Learning Object (203.4 minutes divided among five Learning Objects). Further analysis by the researchers revealed that despite having the lowest time-per-Learning Object rate, one Learning Object in the Assessment of Student Learning unit in particular took the longest to complete compared with all others. This information was used by the writers prior to Year 2 to reduce some of the content and ensure that each of the Learning Objects demanded the same amount of time to complete so as to not overtax the participant. 
Table 3: Quiz data for each Learning Object ( $n$ ranges from 7-11 pilot teachers).

\begin{tabular}{lcccc}
\hline Learning Object & $\begin{array}{c}\text { Avg. } \\
\text { Score }\end{array}$ & $\begin{array}{c}\text { Avg. } \\
\text { Attempts }\end{array}$ & $\begin{array}{c}\text { Max. } \\
\text { Attempts }\end{array}$ & $\begin{array}{c}\text { Total } \\
\text { Submissions }\end{array}$ \\
\hline Action Research & 88 & 5.3 & 14 & 10 \\
Adapting Instruction & 100 & 1.1 & 2 & 11 \\
Best Practices & 100 & 1.9 & 5 & 7 \\
Classroom Quality & 94 & 11.3 & 33 & 7 \\
Data Analysis & 84 & 10.4 & 31 & 9 \\
Designing Standards Based STEM & 98 & 8.9 & 29 & 8 \\
Enhancing Classroom Creativity & 100 & 1.3 & 3 & 7 \\
Formative Evaluation Techniques & 98 & 2.0 & 10 & 11 \\
Implementing Learning Activities & 100 & 1.9 & 4 & 7 \\
Initial Student Evaluation & 98 & 2.5 & 7 & 8 \\
Lab and Class Management & 100 & 1.0 & 1 & 9 \\
Multiculturalism in the Classroom & 100 & 1.6 & 3 & 7 \\
Professional Organizations & 100 & 5.1 & 10 & 7 \\
School and Community & 100 & 1.1 & 2 & 7 \\
STEM Curricula & 100 & 1.3 & 2 & 9 \\
Student Organizations & 100 & 1.8 & 4 & 6 \\
Working with Special Populations & 100 & 1.9 & 6 & 7 \\
\hline
\end{tabular}

There was a lack of supportive media, such as instructive video clips, in the majority of the Year 1 Learning Objects, and while pilot teachers did not communicate concerns of this absence, it became one of the foci of the summer writing workshop following Year 1. Writers subsequently incorporated relevant images, infographics, and instructional videos to add interest and depth to the content.

\section{Artifacts/evidences}

When pilot teachers follow the procedures outlined in each Learning Object to implement the $\mathrm{T}^{2} \mathrm{I}^{2}$ content in their classrooms, they are demonstrating practices that align with National Board standards. As such, the Unit entries that teachers submit are also in alignment with National Board submissions, however at a scaled-down proportion. Written commentaries for $\mathrm{T}^{2} \mathrm{I}^{2}$ are 2 pages typed compared with 11 pages for NBC, and video commentaries are 5 minutes long for $\mathrm{T}^{2} \mathrm{I}^{2}$ as opposed to 20 minutes for NBC. ${ }^{10}$ These written and audiovisual artifacts require teachers to provide evidence of their ability to manage a learning environment, monitor a learning environment, adjust a learning environment to improve instruction, conduct selfassessment, and contribute to a learning community.

The Year 1 pilot teachers who successfully completed all four Units in the $\mathrm{T}^{2} \mathrm{I}^{2}$ program submitted a total of six artifacts: four written commentaries and two video commentaries. A National Board Certified teacher in CTE scored all of the submissions on a 4-point scale, and the metrics in each of the scoring matrices were adapted or directly quoted from National Board 
scoring guidelines, which can be found online. ${ }^{11}$ The highest score a participant can earn is a 4 , and the National Board considers a 3 to be excellent. A summary of teacher performances can be found in Table 4 .

Table 4: Teacher performance data.

\begin{tabular}{lcc}
\hline Unit Submission & $n$ & $\begin{array}{c}\text { Mean score } \\
(\max .=4)\end{array}$ \\
\hline Assessment of Student Learning: Written Commentary & 6 & 2.50 \\
Demonstration Lesson: Written Commentary & 4 & 2.92 \\
Demonstration Lesson: Video Capture & 4 & 3.00 \\
Fostering Teamwork: Written Commentary & 4 & 3.00 \\
Fostering Teamwork: Video Capture & 4 & 2.33 \\
Documented Accomplishments: Written Commentary & 5 & 2.55 \\
\hline Total & 27 & 2.69 \\
\hline
\end{tabular}

Overall, teachers' average scores were just below or equal to 3.0, the standard of excellence as defined by the National Board out of a possible 4.0. Based on these data points, Year 1 pilot teachers have demonstrated the ability to reflect on their teaching practices and provide evidence of managing learning environments, with ample room for improvement. This evidence points to the need for professional development materials like $\mathrm{T}^{2} \mathrm{I}^{2}$ in conjunction with ongoing support and feedback for participants to further improve their reflection and practice.

It should be noted that the maximum number of unit submissions $(n)$ is 6 and not 16. Although all 16 pilot teachers had intended and committed to participate in the $\mathrm{T}^{2} \mathrm{I}^{2}$ program for Year 1, various circumstances prevented them from doing so. As such, four teachers submitted all six unit entries, one teacher submitted two of the six unit entries, and another teacher submitted one unit entry. Seven teachers read all of the Learning Objects, and four read only some.

\section{Student STEM pre-assessment}

In addition to the online professional development content, pilot teachers in the $\mathrm{T}^{2} \mathrm{I}^{2}$ program were asked to implement an engineering design lesson and administer pre- and post-tests to students to determine student learning gains in science, mathematics and technology/engineering. The pre-assessment was comprised of 30 multiple-choice questions - 10 each in science, mathematics and technology/engineering. Experts in each discipline wrote a bank of 20 questions for both the middle school and the high school levels, and 10 questions in each subject were chosen for the pre-assessment. (See Tables 5 and 6 for student performance results and Appendix B for sample questions.) 
It was realized late in the pilot year that some of the items on the high school pre- and post-tests were incorrect. Pilot teachers were notified of the mistake, but unfortunately some had already administered the tests and submitted them to the $\mathrm{T}^{2} \mathrm{I}^{2}$ staff for data entry and analysis. Therefore, modifications could not be made without nullifying the tests. Tests were modified prior to the Year 2 pilot.

Table 5: Student performance - middle school $(n=34)$.

\begin{tabular}{llll}
\hline Discipline & $\begin{array}{l}\text { Mean Pre-test Score } \\
(\max .=10)\end{array}$ & $\begin{array}{l}\text { Mean Post-test Score } \\
(\max .=10)\end{array}$ & Mean Delta \\
\hline Mathematics & 3.46 & 3.47 & 0.02 \\
Science & 3.73 & 3.24 & -0.49 \\
Technology & 4.39 & 4.04 & -0.36 \\
\hline
\end{tabular}

Table 6: Student performance - high school $(n=10)$.

\begin{tabular}{llll}
\hline Discipline & $\begin{array}{l}\text { Mean Pre-test Score } \\
(\max .=10)\end{array}$ & $\begin{array}{l}\text { Mean Post-test Score } \\
(\max .=10)\end{array}$ & Mean Delta \\
\hline Mathematics & 4.70 & 5.40 & 0.70 \\
Science & 3.20 & 4.30 & 1.10 \\
Technology & 3.40 & 5.00 & 1.60 \\
\hline
\end{tabular}

\section{Unit implementation}

Two of the International Technology and Engineering Educators Association's Engineering by Design (EbD) lessons were chosen for teachers to implement - lunar colonization at the middle school level and a basketball launcher at the high school level. It was intended that a teacher would require approximately 10 days to execute the lesson. EbD was chosen because all five of the participating states (IL, KY, OH, NC, and VA) were cohort states with EbD, therefore the curriculum was readily available to technology and engineering design teachers in each of the states. Also, the probability that teachers were already implementing EbD (or similar) lessons was high, thus the lesson would not require new teaching.

It is worth noting that the EbD unit implementation functioned as an ancillary activity for teachers so that the researchers could measure if the $\mathrm{T}^{2} \mathrm{I}^{2}$ content supported student learning gains in mathematics, science, and technology/engineering. The participants were not required to complete their unit submissions during the EbD unit execution. Rather, they could choose any lessons at multiple points in the year in which to complete their written and video commentaries. 
In September 2012, the pilot teachers received a package containing a print-out of the PowerPoint document for the grade-appropriate lesson, 30 copies each of the pre-tests and posttests, 60 copies of answer sheets for both the pre-tests and post-tests, postage-paid envelopes for mailing the completed tests, and a flash drive containing electronic versions of all materials. Throughout the Year 1 pilot, teachers expressed the need for more guidance with the EbD lessons. For example, there was no indication in the PowerPoint how much time the lesson would require for implementation. Also, there were no introductory documents highlighting stipulations, if any, about when teachers should implement the lesson in the school year or if it must coincide with completion of the $\mathrm{T}^{2} \mathrm{I}^{2}$ curriculum. Due to this lack of clarity, primary investigators determined that teachers should be given a pacing guide and simplified lesson materials in Year 2 to ameliorate confusion.

\section{Student STEM post-assessment}

At the conclusion of the Engineering by Design unit, students completed a 30-item multiplechoice assessment whose items were parallel to the pre-assessment. The post-assessment was administered on the last day of the unit to measure if there were any student knowledge gains as a result of participating in the EbD unit. Although student learning gains in science, mathematics and technology/engineering were not the primary focus of research for the $\mathrm{T}^{2} \mathrm{I}^{2}$ program, student performances were measured to determine if the $\mathrm{T}^{2} \mathrm{I}^{2}$ system supported student learning in addition to teacher competencies. It was not expected that student gains would be significant. (Data from Year 1 student assessments are in Tables 5 and 6.) At the middle school level, students showed insignificant gains in mathematics, and no gains in science and technology/engineering $(n=34)$. At the high school level, students showed gains in all three disciplines. (It should be noted, however, that the number, $n$, of high school students' results is only 10.)

Based on analyses of student results on pre/post tests, teacher participation in National Boardaligned professional development does not necessarily support student competency development specific to the learning of science, mathematics, and technology/engineering at the middle school level. It is believed that the situated learning environment paired with preexisting curricula implementation of technology education pilot sites may have contributed to the marginal competency progressions in science and technology learning at the high school level.

\section{Conclusions}

The Year 1 pilot of the $\mathrm{T}^{2} \mathrm{I}^{2}$ project was influential in effecting necessary modifications for the subsequent pilot year. As the first in three pilot years, Year 1 precipitated changes in virtually every aspect of the curriculum, from the number of participants to the content of the engineering design lesson.

Due to the low participation rate of the pilot teachers, the number of chosen applicants for the Year 2 pilot was increased from 16 to 20. In an effort to better encourage participation, converse with teachers, and clarify goals of the project, a webinar was designed for Year 2 pilot teachers. Although the data collected show connections between the implementation of $\mathrm{T}^{2} \mathrm{I}^{2}$ and gains in 
student learning and teacher classroom practices, the low number of teacher participants and student test submissions does not allow results to be generalized to wider populations.

Despite the fact that the STEM discipline experts evaluated the units of instruction for Year 1 for standards alignment and constructed the pretests and posttests, there were errors in some of the tests and the lessons did not clearly define time and structure for teachers. The same panel of experts consulted after Year 1 to reconfigure the lessons for efficiency and clarity, and they developed support materials and links to resources to assist teachers further. Additionally, pretests and posttests were corrected and in some cases rewritten to increase their validity for Year 2. Much has been learned in the first pilot year of the $\mathrm{T}^{2} \mathrm{I}^{2}$ project. At the conclusion of the Year 2 pilot, data and feedback will be analyzed to inform future modifications.

Any opinions, findings, and conclusions or recommendations expressed in this material are those of the authors and do not necessarily reflect the views of the National Science Foundation.

\section{Bibliography}

\footnotetext{
${ }^{1}$ DuBois, B., Farmer, C., Gomez, L., Messner, R., Silva, E. (2009, Summer). Increasing STEM capacity though "Learn-by-doing” pedagogy. In Proceedings: 2009 Educational Leadership STEM Symposium, 2. California Polytechnic State University: San Luis Obispo, CA.

${ }^{2}$ Guskey, T. R. (2003). What makes professional development effective? The Phi Delta Kappan, 84(10), 748-750. Retrieved from http://www.jstor.org/stable/20440475

${ }^{3}$ Mundry, S. (2007). Professional development in science education: What works? Retrieved from http://www.conferences.ilstu.edu/NSA/papers/Mundry.pdf

${ }^{4}$ Darling-Hammond, L., \& McLaughlin, M. W. (1995). Policies that support professional development in an era of reform. The Phi Delta Kappan, 76(8), 597-604.

${ }^{5}$ Lustick, D. \& Sykes, G. (2006). National Board Certification as professional development: What are teachers learning? Retrieved from http://www.nbpts.org/resources/research/browse_studies?ID=18

${ }^{6}$ Guskey, T. R., \& Yoon, K. S. (2009). What works in professional development? The Phi Delta Kappan, 90(7), 495-500.

${ }^{7}$ The Center for Comprehensive School Reform and Improvement. (2006, November). 7 actions that improve school district performance. Retrieved from http://www.centerforcsri.org/files/TheCenter_NL_Nov06.pdf

${ }^{8}$ Ernst, J. V., Clark, A. C., DeLuca, V. W., Bottomley, L. (2013). Professional development system design for grades 6-12 technology, engineering, and design educators. In ASEE Conference. Paper ID \#6184.

${ }^{9}$ Transforming Teaching Through Implementing Inquiry. (2013). Learning objects. Retrieved from http://t2i2.ncsu.edu

${ }^{10}$ National Board for Professional Teaching Standards. (2013). Early adolescence through young adulthood, career and technical education: Portfolio instructions. Retrieved from http://www.nbpts.org/sites/default/files/documents/certificates/PFInstructions/EAYA_CTE_Portfolio_Instructions_072313.pdf

${ }^{11}$ National Board for Professional Teaching Standards. (2013). Early adolescence through young adulthood, career and technical education: Scoring guide for candidates. Retrieved from http://www.nbpts.org/sites/default/files/documents/certificates/nbpts-certificate-eaya-cte-scoring.pdf
} 
Appendix A - Unit Submission Requirements and Prompts ${ }^{9}$

\section{Demonstration Lesson}

\section{Topics covered in this unit:}

Lab and Class Management

Designing Standards Based STEM

STEM Curricula

\section{Required Supplemental Documents}

Video Capture \#1

Written Commentary

\section{Video Capture \#1}

\section{Document Requirements}

Please identify a demonstration lesson that you plan to incorporate in your classroom instruction. Based on your previous personal practice informed/incorporated with the information conveyed in the "Demonstration Lesson" cluster of learning objects, please depict the following (5 minutes in length):

1. Your explanation and demonstration of the progression of steps

2. Your interactions with students as they perform the demonstrated skill

3. Your monitoring of performance while providing feedback and addressing student questions

\section{Written Commentary}

\section{Document Requirements}

Please consider the demonstration lesson that you planned and recorded. Based on your personal practice informed/incorporated with the information conveyed in the "Demonstration Lesson" cluster of learning objects, please explain the following (no more than 2 pages in length):

1. How you established a safe learning environment where all students are encouraged

2. How the demonstration lesson relates to course learning goals and national standards

3. How you incorporated appropriate technologies to enhance learning 


\section{Appendix B - Sample pre-test questions for middle school and high school.}

\section{MIDDLE SCHOOL:}

A building wall is 20 yards long. The building is being drawn with scale of 1 inch $=2$ feet. How many inches long will the wall be in the sketch?
a. 10 inches
b. 20 inches
c. 30 inches
d. 60 inches

Why is the gravitational force on the surface of the moon less then the gravitational force on the surface of the earth?
a. The moon is far away from the earth
b. The moon has a smaller radius than the earth
c. The moon is less dense than the earth
d. The moon has less mass than the earth

Two-dimensional representations of design solutions include thumbnail sketches, dimensioned drawings, and CAD drawings. Three-dimensional representations include:
a. Physical models and prototypes
b. Conceptual models and mock-ups
c. Rendered CAD drawings and prototypes
d. Physical models and conceptual models

\section{HIGH SCHOOL:}

If a ping pong ball has a force of $0.04158 \mathrm{~N}\left(\mathrm{~kg} \mathrm{~m} / \mathrm{s}^{2}\right)$ and a mass of $0.0027 \mathrm{~kg}$, what is its acceleration?
a. $\quad 15.4 \mathrm{~m} / \mathrm{s}$
b. $\quad 6.49 \mathrm{~m} / \mathrm{s}$
c. $0.06493 \mathrm{~m} / \mathrm{s}$
d. $\quad 0.0388 \mathrm{~m} / \mathrm{s}$

You want to design a catapult that would launch a table tennis ball or a golf ball along the same ideal trajectory. Which of the following is true?
a. More force is required for the golf ball.
b. More force is required for the table tennis ball.
c. The launch angle for the golf ball must be less than the table tennis ball.
d. The launch angle for the table tennis ball must be less than the golf ball.

Using a bicycle as an example, which is a major factor affecting its mechanical efficiency?
a. Strength of the rider
b. Strength of the frame crossbar
c. Size of the drive gear
d. Length of the brake cable 